\title{
Radiomanganese Distribution to Female and Male of Haliotis discus at the Post-Spawning Stage
}

\author{
Kunio Ikuta*1 and Motokazu Nakahara*2 \\ (Accepted December 4, 1985)
}

\begin{abstract}
Immediately after spawning had occurred in the early stage of exposure experiment, the female individuals exposed to ${ }^{54} \mathrm{Mn}$ concentrated more actively the nuclide than the males, and retained it in whole bodies at 1.70 times higher compared to the males in $100 \%-\mathrm{SW}$. Moreover, the biological half-life estimated from the excretion formula was 1.58 times longer in the females than in the males, i.e. ${ }^{34} \mathrm{Mn}$ in the females was eliminated more gradually than that in the males. These results differed clearly from those obtained on $H$. discus at the pre-spawning stage and furthermore, from stable-Mn distribution observed in females and males of Mytilus edulis at the post-spawning season presented previously elsewhere.

${ }^{54} \mathrm{Mn}$ distributed to various soft tissues in the females were apparently higher than those in the males at the end of the exposure in $100 \%-\mathrm{SW}$. The concentration factor for ovary of specimens in $100 \%$-SW raised up to 990 at the end of the exposure, while that of spermary was only 146. The difference between that for the ovary and the spermary was of the highest value among tissues, and consequently a similar correlationship existed in absolute amounts and concentrations. The distribution of ${ }^{54} \mathrm{Mn}$ to ovary exhibited similar trend at the pre- and the post-spawning stages, but its degree differed from each other and was enhanced in concentration at the latter stage.

The nuclide uptake, retention and excretion by the females were inhibited under depressed specific gravity condition, whereas the males were not affected at all.
\end{abstract}

Manganese is required biologically as one of essential trace elements in animals, and it is remarkably concentrated in ovaries of bivalve and gastropod molluscs, such as Crassostrea virginica, ${ }^{1)}$ Patinopecten (Mizuhopecten) yessoensis, ${ }^{2)}$ Batillus cornutus, ${ }^{3)}$ Haliotis discus, ${ }^{4,3)}$ and probably Mytilus edulis, ${ }^{8)}$ compared to those spermaries according to their respective cycles of reproduction, especially at the pre-spawning stages bearing developed gonads. Ikuta ${ }^{4}$ revealed that in $H$. discus at the pre-spawning stage, stable-Mn concentration in whole body included conch and soft part of females was equivalent to that of males, but the metal concentration in conchs was significantly higher in males than in females, and in soft parts the correlation was inverted. Moreover, in soft parts, distribution rates of stable-Mn in ovaries and feet differed greatly between both sexes, i.e. in the former the rate was higher in females than in males, while in the latter higher in males. The ${ }^{54} \mathrm{Mn}$ behaviour to females and males of black abalones was examined by Ikuta and Nakahara $^{5 /}$ at the pre-spawning stage, and they demonstrated that the intersexual difference of the nuclide was recognized only in gonads, and the concentration was significantly higher in ovary than in spermary after short exposure period in laboratory condition.

In the present paper, at the post-spawning stage, ${ }^{54} \mathrm{Mn}$ behaviours to females and males of black abalones were examined individually under two different specific gravities, i.e. $100 \%$-seawater $(100 \%-\mathrm{SW})$ as seen for that of coastal water and extremely low $60 \%$-seawater $(60-\% \mathrm{SW})$. The results obtained here were regressed to accumula tion and excretion curves, and intersexual differences for ${ }^{54} \mathrm{Mn}$ behaviour to black abalones were discussed.

\section{Materials and Methods}

The abalones employed in this study had been raised during about two years from their larval stage immediately after spawning in the land installation at Seed Production Section, Ibaraki Prefectural Fisheries Experimental Station.

\footnotetext{
*1 Laboratory of Aquatic Environment and Ecology, Department of Fisheries, Faculty of Agriculture, Miyazaki University, Miyazaki 889-21, Japan (生田國雄：宮崎大学農学部).

*2. Division of Marine Radioecology, Nakaminato Branch, National Institute of Radiological Sciences, Nakaminato, Ibaraki 311-12, Japan (中原元和：放射楾医学研究所海洋放射生態学研究部).
} 
Table 1. Sizes and weights of specimens, and rearing conditions

\begin{tabular}{|c|c|c|c|c|c|c|}
\hline \multirow{2}{*}{ Group } & \multirow{2}{*}{$\begin{array}{c}\text { Sex \& } \\
\text { number }\end{array}$} & \multirow{2}{*}{ S, L. } & \multicolumn{2}{|c|}{ Uptake } & \multicolumn{2}{|c|}{ Excretion } \\
\hline & & & W. T. & Sp. Gr. & W. T. & Sp. Gr. \\
\hline \multirow{2}{*}{$100 \%-S W$} & $\mathrm{~F}(17)$ & $6.53 \pm 0.3434 .06 \pm 5.77$ & $19.5 \pm 0.4$ & \multirow{2}{*}{1.02536} & $19.5 \pm 0.4$ & \multirow{2}{*}{1.02537} \\
\hline & $\mathrm{M}(18)$ & $6.24 \pm 0.3027 .67 \pm 4.36$ & $19.6 \pm 0.4$ & & $19.5 \pm 0.4$ & \\
\hline \multirow{2}{*}{$60 \%-S W$} & $F(12)$ & $6.39 \pm 0.33 \quad 37.85 \pm 6.74$ & $19.5 \pm 0.3$ & \multirow{2}{*}{1.01552} & $19.4 \pm 0.4$ & \multirow{2}{*}{1.01583} \\
\hline & $\mathrm{M}(12)$ & $6.22 \pm 0.2733 .10 \pm 5.25$ & $19.6 \pm 0.3$ & & $19.5 \pm 0.4$ & \\
\hline
\end{tabular}

S.L., W.W., W.T. and Sp. Gr. are abbreviated from shell length, whole weight, water temperature and specific gravity, and units are centimeter for the first, gramme for the second and centigrade for the third. Values of Sp. Gr. are converted to those at $15^{\circ} \mathrm{C}$,

The gamma-emitting radioisotope ${ }^{54} \mathrm{Mn}\left(\mathrm{MnCl}_{2}\right.$ in $0.5 \mathrm{M} \mathrm{HCl}$, specific activity: $48.33 \mathrm{mCl} / \mathrm{mg} \mathrm{Mn}$; stock solution diluted with deionized water: 1.16 $\mathrm{mCi} / 50 \mathrm{~m} l$ ) was used in the experiment. Rearing seawaters $(60 l)$ had previously been spiked with the nuclide at certain concentrations by addition of $1 \mathrm{ml}$ of the stock solution to expose black abalones separated sexually. Seawaters of two specific gravities, $100 \%-\mathrm{SW}$ and $60 \%$-SW groups, were prepared to examine salinity effect on uptake, retention and excretion for the nuclide by abalones and the water temperature for rearing was almost nearly adjusted to that of natural environment at the season, as listed in Table 1.

During the exposure experiment, rearing seawaters were exchanged with fresh labeled seawaters to maintain relatively constant levels of the nuclide on the zero (the beginning of exposure), $3 \mathrm{rd}$, 6th, 9th, 12th and 15th days, and those activities were regularly counted every morning. The measurements were converted to counts per minute per milliliter $(\mathrm{cpm} / \mathrm{ml})$ and averaged. Throughout 19 days' exposure period, intact individual specimens in each experimental group were removed from the labeled seawaters, counted individually by a whole body counter on the 1 st, $3 \mathrm{rd}$, 6th, 9th, 12th, 15th and 19th (the end of exposure) days and returned into each aquarium. The measurements obtained were expressed as counts per minute per gramme fresh weight $(\mathrm{cpm} / \mathrm{g}$ fresh wt) and used to estimate concentration factors at steady state together with activities in rearing seawaters.

During the excretion experiment that specimens were held in non-labeled seawaters exchanged every other day over 25 days, residual radioactivities in whole bodies were individually counted on the zero (equal to the 6th day of exposure experiment), 1st, $2 \mathrm{nd}, 4 \mathrm{th}, 7 \mathrm{th}, 10 \mathrm{th}, 18 \mathrm{th}$ and 25 th days.

Regression curves for accumulation were com- puted using the following equation,

$$
\mathrm{Y}=\mathrm{A}\left(1-\mathrm{e}^{-\mathrm{bt}}\right) \text {, }
$$

in which ' $Y$ ' is concentration factor for whole body at time ' $t$ ' in day, ' $A$ ' represents an asymptote, and ' $b$ ' is a regression coefficient as substituted for an excretion rate that is induced from the equation of excretion described below. Excretion curves were expressed as

$$
\mathbf{Y}=\mathbf{a} e^{-b t},
$$

in which ' $Y$ ' is retention rate adjusted radioactivity on the zero day in excretion experiment to $100 \%$, and ' $a$ ' represents an intercept cross the $Y$ axis on zero day, and ' $b$ ' is a regression coefficient represented as an excretion rate.

At the end of exposure experiment, radioactivities in whole soft bodies (WSB), various tissues (i.e. foot (FT), mantle (ME), gill (GL), gonad (GD), digestive diverticulum (DD), buccal mass (BM) and remains (RS)) and whole bodies (WB) were counted, and those were altered to absolute amounts, absolute amount percents, and concentration factors.

\section{Results}

In the acclimation to experimental conditions and in the early stage within a few days after the beginning of exposure, all the members of black abalones kept in aquaria had spawned, in turn, at several times, by physical stimuli, i.e. a series of handling to count activity, such as taking off from substratum, exposure to air, wrapping with a sheet to prevent contamination, counting and returning to each aquarium, and thereafter, they had turned physiologically into spent condition.

There were no significant differences among initial levels of activities of rearing seawaters as changed over six times: $220 \pm 3.5$ and $219 \pm 6.2$ $(\mathrm{cpm} / \mathrm{ml})$ for females and males in $100 \%-\mathrm{SW}$ 
Table 2. Concentration factors for whole bodies of females and males in $100 \%-\mathrm{SW}$ and $60 \% \mathrm{sW}$ groups during uptake experiments

\begin{tabular}{rccccc}
\hline & \multicolumn{3}{c}{ Concentration Factor } \\
\cline { 2 - 3 } Days & \multicolumn{2}{c}{$100 \%$-SW } & & \multicolumn{2}{c}{$60 \%$-SW } \\
\cline { 2 - 3 } \cline { 5 - 6 } & Female & Male & & Female & Male \\
\hline 1st & $15 \pm 2.0$ & $19 \pm 2.8$ & & $10 \pm 1.6$ & $10 \pm 1.4$ \\
3rd & $38 \pm 4.8$ & $40 \pm 2.5$ & & $22 \pm 3.4$ & $23 \pm 2.8$ \\
6th & $70 \pm 8.6$ & $56 \pm 6.5$ & & $43 \pm 6.9$ & $43 \pm 6.0$ \\
9th & $87 \pm 11$ & $69 \pm 3.5$ & & $55 \pm 6.5$ & $66 \pm 5.7$ \\
12th & $109 \pm 18$ & $84 \pm 7.4$ & & $65 \pm 7.2$ & $88 \pm 7.1$ \\
15th & $132 \pm 19$ & $97 \pm 11$ & & $86 \pm 8.1$ & $97 \pm 13$ \\
19th & $168 \pm 23$ & $119 \pm 17$ & & $95 \pm 6.7$ & $113 \pm 15$ \\
\hline
\end{tabular}

groups, respectively, $225 \pm 4.1$ and $219 \pm 4.6$ $(\mathrm{cpm} / \mathrm{ml})$ in $60 \%-\mathrm{SW}$ group, respectively. Residual activities in rearing seawaters fluctuated with similar decreasing trends, and $196 \pm 30.9$ and $212 \pm 10.9(\mathrm{cpm} / \mathrm{m} /)$ for females and males of $60 \%-\mathrm{SW}$ group were apparently higher than $175 \pm 29.1$ and $154 \pm 27.1(\mathrm{cpm} / \mathrm{ml})$ for females and males of $100 \%-\mathrm{SW}$ group, respectively. However, any significant relationships could not be found between activities in rearing seawaters.

The regression analysis to the equation (1) was applied to concentration factors calculated from ratios (activity in whole body/activity in seawater) listed in Table 2. In excretion experiment, retention rates $(\%)$ for residual activities in whole bodies were regressed to the equation (2). Regression coefficients in the equation (2) were applied to excretion rates in the equation (1). The predicted formulae for accumulation were given in
Table 3 with confidence limits $(90,95$ and $99 \%$ levels) for regression coefficients and figures for ' $A$ ' and ' $b$ ' at each level. The figures on accumulation of the four lots were regressed to the equation (1) with good fitness at a confidence limit of $99.9 \%$. The highest value for ' $\mathrm{A}$ ' that represented an asymptote of an accumulation curve was found of females in $100 \%-\mathrm{SW}$ group and raised up to 240 , which corresponded to the concentration factor at steady state. In $100 \%-\mathrm{SW}$ group, the ratio of concentration factor at steady state for females to those for males was given as 1.70 . This demonstrates distinctly that accumulation and/or retention abilities for ${ }^{54} \mathrm{Mn}$ in females differ from those of males. Salinity effect occurred distinctively in females, i.e. the concentration factor at steady state for females in $60 \%-\mathrm{SW}$ was depressed to $52.5 \%$, when compared to that for $100 \%-\mathrm{SW}$ females, while in males, the concentration factors for both groups were comparable to each other. Therefore, it is inferred that salinity effect on males could not occur. The concentration factor at steady state for $100 \%$ SW females differed significantly $(p<0.05)$ from those of $100 \%$-SW males, $60 \%$-SW females and $60 \%$-SW males which were comparable to one another.

On the 6th day in process of exposure phase, the half numbers of specimens were transferred to excretion phase, in which they kept in nonlabeled seawaters for 25 days and during the period, the radioactivities in whole bodies were counted at intervals. The predicted curves for excretion had not good fitness to plotted dots at

Table 3. Predicted formulae, and $\mathrm{A}$ and $\mathrm{b}$ values estimated from confidence limit for regression coefficient

\begin{tabular}{|c|c|c|c|c|c|c|c|}
\hline \multirow{2}{*}{ Group } & \multirow{2}{*}{ Sex } & \multirow{2}{*}{ Predicted formula } & \multirow{2}{*}{ C. L. } & \multicolumn{2}{|c|}{ Upper limit } & \multicolumn{2}{|c|}{ Lower limit } \\
\hline & & & & A & $\mathrm{b}$ & A & $\mathrm{b}$ \\
\hline \multirow{6}{*}{$100 \%-S W$} & \multirow{3}{*}{$\langle\mathbf{F}\rangle$} & \multirow{3}{*}{$Y=240\left(1-e^{-0.055 t}\right)$} & 90 & 293 & 0.045 & 203 & 0.065 \\
\hline & & & 95 & 314 & 0.042 & 194 & 0.063 \\
\hline & & & 99 & 377 & 0.035 & 176 & 0.075 \\
\hline & \multirow{3}{*}{$\langle\mathbf{M}\rangle$} & \multirow{3}{*}{$Y=142\left(1-e^{-0.087 t}\right)$} & 90 & 180 & 0.068 & 116 & 0.106 \\
\hline & & & 95 & 198 & 0.062 & 110 & 0.112 \\
\hline & & & 99 & 255 & 0.048 & 97 & 0.126 \\
\hline \multirow{6}{*}{$60 \%-S W$} & \multirow{3}{*}{$\langle F\rangle$} & \multirow{3}{*}{$Y=126\left(1-e^{-0.088 t}\right)$} & 90 & 153 & 0.057 & 107 & 0.081 \\
\hline & & & 95 & 161 & 0.054 & 104 & 0.084 \\
\hline & & & 99 & 189 & 0.046 & 95 & 0.094 \\
\hline & \multirow{3}{*}{$\langle\mathbf{M}\rangle$} & \multirow{3}{*}{$Y=153\left(1-e^{-0.055 t}\right)$} & 90 & 174 & 0.065 & 136 & 0.073 \\
\hline & & & 95 & 181 & 0.055 & 133 & 0.075 \\
\hline & & & 99 & 202 & 0.049 & 123 & 0.081 \\
\hline
\end{tabular}

Confidence limit is abbreviated to C.L. $(\%)$ 
Table 4. Retention rates (\%) of females and males in $100 \%$-SW and $60 \%$-SW, respectively, during excretion experiment

\begin{tabular}{cccccc}
\hline \multirow{2}{*}{ Days } & \multicolumn{2}{c}{$100 \%-S W$} & & \multicolumn{2}{c}{$60 \%-S W$} \\
\cline { 2 - 3 } & F & M & & F & M \\
\hline Zero & 100 & 100 & & 100 & 100 \\
1st & 81.02 & 79.32 & & 69.63 & 73.76 \\
2nd & 74.69 & 75.09 & & 69.30 & 75.52 \\
4th & 62.51 & 54.06 & & 60.65 & 60.12 \\
7th & 50.42 & 40.81 & & 37.07 & 37.69 \\
10th & 38.82 & 27.55 & & 31.41 & 29.90 \\
14th & 37.77 & 17.71 & & 23.81 & 25.35 \\
18th & 29.08 & 14.99 & & 20.36 & 23.30 \\
25th & 24.65 & 13.07 & & 17.75 & 20.17 \\
\hline
\end{tabular}

the early stage immediately after the beginning of excretion, and thereafter, the plotted dots superimposed on the predicted curves toward the end of experiment. In both groups, it can be suggested that losses of the nuclide were consisted of more than one component. Retention rates in excretion phase were listed in Table 4, in which a similar decreasing trend was seen on females and males in $60 \%-\mathrm{SW}$ group. But, in $100 \%-\mathrm{SW}$ group, those of females were about $10 \%$ or more higher than those of males toward after the 4th day, though they were similar to each other until the 2nd day. In any case, activities lost at the 1 st day were highest by ca. $40 \%$ for $60 \%-\mathrm{SW}$ and

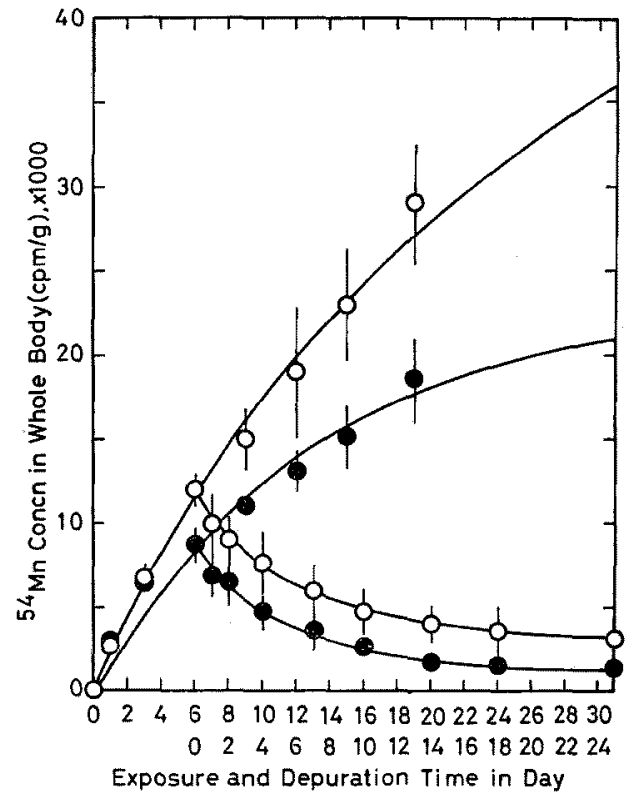

Fig. 1. Accumulation and excretion curves of ${ }^{54} \mathbf{M n}$ by whole bodies of female (open circle) and male (solid circle) reared in $100 \% \mathrm{sW}$. Curves were fitted visually to plotted dots only in depuration time. Data used here are represented as count per minute per gramme of fresh weight. Vertical bar represents one standard deviation, and upper and lower figures attached to the $X$ axis indicate exposure and depuration times, respectively.

Table 5. Absolute amounts (AA, cpm/tissue) and absolute amount percents (AAP, $\%$ ) of ${ }^{54} \mathrm{Mn}$ in various tissues and whole soft bodies, and weight percents (WP) of tissues in $100 \%-\mathrm{SW}$ at the end of exposure

\begin{tabular}{|c|c|c|c|c|}
\hline Tissue & Sex & $\mathrm{AA}$ & AAP & WP \\
\hline \multirow{2}{*}{ FT } & $\langle F\rangle$ & $172,000 \pm 32,200$ & $35.31 \pm 4.24$ & $69.75 \pm 2.35$ \\
\hline & $\langle\mathbf{M}\rangle$ & $120,000 \pm 15,700$ & $43.88 \pm 3.56$ & $65.62 \pm 2.60$ \\
\hline \multirow{2}{*}{$M E$} & $\langle F\rangle$ & $15,200 \pm 2,760$ & $3.12 \pm 0.42$ & $5.55 \pm 0.62$ \\
\hline & $\langle\mathrm{M}\rangle$ & $10,800 \pm \quad 1,420$ & $4.01 \pm 0.58$ & $5.09 \pm 0.45$ \\
\hline \multirow[b]{2}{*}{ GL } & $\langle\mathrm{F}\rangle$ & $19,500 \pm 3,410$ & $4.02 \pm 0.52$ & $2.13 \pm 0.08$ \\
\hline & $\langle\mathrm{M}\rangle$ & $14,700 \pm$ & $5.41 \pm 0.41$ & $2.13 \pm 0.08$ \\
\hline \multirow[b]{2}{*}{ GD } & $\langle\mathrm{F}\rangle$ & $146,000 \pm 95,000$ & $26.10 \pm 8.52$ & $3.95 \pm 0.79$ \\
\hline & $\langle\mathrm{M}\rangle$ & $5,600 \pm \quad 5,000$ & $1.92 \pm 1.50$ & $1.28 \pm 0.42$ \\
\hline \multirow{2}{*}{$\mathrm{DD}$} & $\langle F\rangle$ & $99,600 \pm 26,500$ & $20.12 \pm 3.16$ & $8.89 \pm 0.85$ \\
\hline & $\langle\mathrm{M}\rangle$ & $82,300 \pm 20,000$ & $29.69 \pm 3.62$ & $12.48 \pm 1.78$ \\
\hline \multirow{2}{*}{$\mathrm{BM}$} & $\langle\mathbf{F}\rangle$ & $17,800 \pm$ & $3.76 \pm 0.81$ & $4.48 \pm 0.57$ \\
\hline & $\langle\mathbf{M}\rangle$ & $14,300 \pm$ & $5.38 \pm 1.09$ & $5.08 \pm 0.35$ \\
\hline \multirow{2}{*}{ RS } & $\langle F\rangle$ & $36,900 \pm$ & $7.57 \pm 0.95$ & $5.25 \pm 0.91$ \\
\hline & $\langle M\rangle$ & $26,400 \pm 2,170$ & $9.72 \pm 0.68$ & $8.32 \pm 0.94$ \\
\hline \multirow[b]{2}{*}{ WSB } & $\langle F\rangle$ & $507,000 \pm 166,000$ & 100 & 100 \\
\hline & $\langle\mathrm{M}\rangle$ & $274,000 \pm 37,300$ & 100 & 100 \\
\hline
\end{tabular}

Note: Abbreviation for tissue name is explained in the text. 
Table 6. ${ }^{34} \mathrm{Mn}$ concentrations (cpm/g fresh wt) in various tissues and whole soft bodies in $100 \%$ SW group at the end of exposure

\begin{tabular}{crr}
\hline Tissue & \multicolumn{1}{c}{ Female } & \multicolumn{1}{c}{ Male } \\
\hline FT & $14,300 \pm 1,740$ & $12,100 \pm 216$ \\
ME & $15,900 \pm 990$ & $14,200 \pm 1,110$ \\
GL & $53,500 \pm 6,920$ & $46,100 \pm 1,540$ \\
GD & $193,000 \pm 69,000$ & $25,100 \pm 1,540$ \\
DD & $65,900 \pm 17,000$ & $44,500 \pm 9,770$ \\
BM & $23,400 \pm 1,930$ & $19,300 \pm 3,830$ \\
RS & $41,900 \pm 8,270$ & $21,300 \pm 712$ \\
WSB & $29,000 \pm 6,640$ & $18,200 \pm 1,410$ \\
\hline
\end{tabular}

Table 7. Concentration factors of various tissues and whole soft bodies in $100 \%-\mathrm{SW}$ and $60 \%-\mathrm{SW}$ groups at the end of exposure

\begin{tabular}{lcccccc}
\hline \hline \multirow{2}{*}{ Tissue } & \multicolumn{2}{c}{$100 \%-\mathrm{SW}$} & & \multicolumn{2}{c}{$60 \%-\mathrm{SW}$} \\
\cline { 2 - 3 } \cline { 5 - 7 } & F & M & & F & M \\
\hline FT & $74 \pm$ & 8.9 & $71 \pm 1.2$ & & $42 \pm 5.7$ & $61 \pm 6.2$ \\
ME & $81 \pm$ & 5.6 & $83 \pm 6.3$ & & $42 \pm 3.9$ & $53 \pm 2.0$ \\
GL & $275 \pm 36$ & $269 \pm 9.1$ & & $145 \pm 13$ & $199 \pm 29$ \\
GD & $990 \pm 354$ & $146 \pm 90$ & & $189 \pm 69$ & $214 \pm 26$ \\
DD & $338 \pm 87$ & $259 \pm 57$ & & $187 \pm 36$ & $213 \pm 8.3$ \\
BM & $120 \pm 9.9$ & $112 \pm 22$ & & $71 \pm 4.3$ & $88 \pm 11$ \\
RS & $215 \pm 43$ & $124 \pm 4.2$ & & $103 \pm 15$ & $113 \pm 5.4$ \\
WSB & $149 \pm 34$ & $106 \pm 8.1$ & $66 \pm 5.7$ & $92 \pm 4.3$ \\
\hline
\end{tabular}

ca. $20 \%$ for $100 \%$-SW. Biological half lives from the predicted formulae for excretion were calculated to be 13 and 8 days for females and males in $100 \%-\mathrm{SW}$, respectively, and to be 11 days for both sexes in $60 \%-\mathrm{SW}$

In the early stages of exposure and depuration, accumulation and excretion curves expressed as cpm per fresh gramme weight are shown in Fig. 1. Those regressed patterns are similar to those explained above in concentration factor and retention rate.

The absolute amounts and concentrations of ${ }^{54} \mathrm{Mn}$ in all the tissues and whole soft bodies in $100 \%$-SW at the end of exposure phase were apparently higher in females than in males (Tables $5 \& 6$ ), among which remarkable differences relating to sex were found on those in gonadal tissues with 26.07 and 7.69 times higher levels in ovary, respectively, and 1.85 and 1.59 times higher in whole soft body of females, respectively. The values of absolute amount percent of ${ }^{54} \mathrm{Mn}$ in all the tissues of males were enhanced on account of the difference for the absolute amounts in whole soft bodies between females and males (Table 5), and those of males except for gonads were signi- ficantly higher than those of females. Almost a quarter of the absolute amount in whole soft body of females was distributed to ovary, whereas only about $2 \%$ in spermary. The highest value for concentration factor was found on that of ovary in $100 \%-\mathrm{SW}$, which was significantly higher than those of the other three lots, and than any other tissues (Table 7).

\section{Discussion}

Some papers are published relating to intersexual differences for heavy metal concentrations in bivalves and gastropods. For example, Walting and Walting ${ }^{\theta)}$ found that $\mathrm{Mn}, \mathrm{Cu}$ and $\mathrm{Zn}$ were more concentrated in whole soft bodies of female Cholomytilus meridionalis, but that $\mathrm{Pb}$ and $\mathrm{Bi}$ were more concentrated in those of male, and that no significant differences were found in the concentrations of $\mathrm{Cd}, \mathrm{Fe}, \mathrm{Co}, \mathrm{Ag}, \mathrm{Ni}$ and $\mathrm{Cr}$. Orren et $a .^{7)}$ analyzed some heavy metals in whole soft bodies of the same species on two occasions, pre- and post-spawning seasons, and found that $\mathrm{Mn}, \mathrm{Fe}, \mathrm{Cu}$ and $\mathrm{Zn}$ were concentrated in those of female higher than male only before a major spawning event, and no significant difference were found after spawning had occurred. Latouche and $\mathrm{Mix}^{\mathrm{B})}$ demonstrated that $\mathrm{Mn}$ and $\mathrm{Zn}$ were more concentrated in female than in male gonadal tissues of Mytilus edulis and there were no significant difference between gonadal concentrations of $\mathrm{Ni}, \mathrm{Cu}$ or $\mathrm{Cd}$. They supposed that the two metals ( $\mathrm{Mn}$ and $\mathrm{Zn}$ ) may be related in a quantitative way to gametogenesis, and $\mathrm{Ikuta}^{2-43}$ and Ikuta and Nakahara ${ }^{5)}$ revealed that the three species, one bivalve and two gastropods, exhibited intersexual differences for stable-Mn distribution and biokinetic behaviours of ${ }^{54} \mathrm{Mn}$. Among these studies $^{\mathrm{i}-8)}$ mentioned above, only Orren et al. ${ }^{7}$ ) had conducted a comparison for stable heavy metal concentrations between pre- and postspawning seasons. Except for the article on ${ }^{54} \mathrm{Mn}$ distribution to females and males of black abalones $^{5)}$ some stable metals had been only analyzed in all the cases. ${ }^{-4,8-8)}$ Therefore, biokinetic behaviours for metals could not enough be understood yet. In many cases, stable metals retained in soft bodies were analyzed only at prespawning season or certain stages of respective cycles of reproduction, and discussed intersexually.

At the pre-spawning stage, it was demonstrated in the previous paper ${ }^{5)}$ that black abalones took 
up ${ }^{54} \mathrm{Mn}$ equivalently in those whole bodies (conchs and soft parts) irrespective of sex over the two weeks' exposure, but the intersexual difference for ${ }^{54} \mathrm{Mn}$ contents was clearly confirmed only in gonads with the ratios of radioactivities in ovary to those in spermary, 3.7 in concentrations $(\mathrm{cpm} / \mathrm{g}$ fresh wt) and 6.10 in total activity (cpm/tissue), and there were no differences relating to sex for those in the other tissues. In the present study, at the post-spawning stage, but still, it was revealed that ${ }^{54} \mathrm{Mn}$ was accumulated more actively in whole bodies of females than in those of males, with the ratio of concentration factors at steady state between sexes reared in $100 \% \mathrm{sW}, 1.70$. Moreover, the biological half life was longer in females than in males in $100 \%$-SW.

These facts will manifest reasonably that the response to ${ }^{54} \mathrm{Mn}$ of black abalones at the prespawning stage differ extremely from those immediately after spawning, i.e. in the latter physiological condition females take up more actively, retain higher and eliminate slower ${ }^{54} \mathrm{Mn}$ than males do. Under depressed specific gravity condition, uptake, retention and excretion abilities of ${ }^{54} \mathrm{Mn}$ are inhibited in females down to those of males.

\section{Acknowledgment}

The first author wishes to express appreciation to the admission of his being a visiting scientist of National Institute of Radiological Sciences, and to the guidance of handling for nuclides and the operation of experimental facilities by $T$. Ueda, the head of Division of Marine Radioecology, Nakaminato Branch, where the radiological part in this study was done.

\section{References}

1) P. S. Galtsoff: Fish. Bull, U. S. Fish Wild. Serv., 64, 383-390 (1964).

2) K. Ikuta: Bull. Fac. Agr., Miyazaki Univ., 32, 93-102 (1985).

3) K. Ikuta: Bull. Fac. Agr., Miyazaki Univ., 32, 85-91 (1985).

4) K. Ikuta: Bull. Fac. Agr., Miyazaki Univ., 32, 103-111 (1985).

5) K. Ikuta and M. Nakahara: Bull. Japan. Soc. Sci. Fish., 52, 1081-1087 (1986).

6) H. R. Watling and R. J. Watling: Mat. Pollut. Bull., 7, 91-94 (1976).

7) M. J. Orren, G. A. Eagle, H. F.-K. O. Henning, and A. Green: Mar. Pollut. Bull., 11, 253-257 (1980).

8) Y. D. Latouche and M. C. Mix: Mar. Pollut. Bull., 13, 277-229 (1982). 